\title{
A Test of the Sustainability Vision Theory: Is It Practical?
}

\author{
Nijsiree Vongariyajit and Sooksan Kantabutra *D \\ Center for Research on Sustainable Leadership, College of Management, Mahidol University, \\ Bangkok 10400, Thailand; nijsiree.v@hotmail.com \\ * Correspondence: sooksan.kan@mahidol.ac.th
}

check for

updates

Citation: Vongariyajit, N.; Kantabutra, S. A Test of the Sustainability Vision Theory: Is It Practical? Sustainability 2021, 13, 7534 https://doi.org/10.3390/su13147534

Academic Editor: Ioannis Nikolaou

Received: 2 June 2021

Accepted: 1 July 2021

Published: 6 July 2021

Publisher's Note: MDPI stays neutral with regard to jurisdictional claims in published maps and institutional affiliations.

Copyright: (C) 2021 by the authors. Licensee MDPI, Basel, Switzerland. This article is an open access article distributed under the terms and conditions of the Creative Commons Attribution (CC BY) license (https:// creativecommons.org/licenses/by/ $4.0 /)$.

\begin{abstract}
Since little is theoretically and empirically known about the characteristics of organizational visions that support corporate sustainability, the present study attempts to answer the following questions: (1) What are the characteristics of an organizational vision that promotes sustainability performance? (2) How does such a vision lead to corporate sustainability? The present study examines a Sustainability Vision theory by simulating a retail store environment that comprises Sustainability Vision, Vision Communication, Empowerment of Staff, Motivation of Staff, and Staff Satisfaction variables. A model expressing the relationships among these variables was quantitatively tested by using data from a sample of retail stores in the Bangkok Metropolitan area. Results revealed that visions characterized by brevity, clarity, future orientation, stability, challenges, abstractness and an ability to inspire, and which contain imageries about improving sales, leadership, and customer and staff satisfaction indirectly and directly predict improved store sustainability prospects via Staff Satisfaction. The vision realization variables of Vision Communication, Empowerment of Staff and Motivation of Staff also enhance the vision effects. The present study is among the first few reported studies which identifies vision characteristics supportive of corporate sustainability. It also contributes to the theoretical literature by endorsing the Sustainability Vision theory and offering some directions for further theoretical development. In terms of its contribution to policy and practice, the present study offers some important managerial implications for retail store managers as to how they should espouse a vision that improves the prospect of store sustainability performance.
\end{abstract}

Keywords: sustainability vision; corporate sustainability; retail; sustainable leadership; organizational culture

\section{Introduction}

Unlike a decade ago, the business world is now rife with uncertainties. Clearly, how corporations respond to these uncertainties essentially determines their sustainable competitiveness and survival. The corporate sustainability literature [1-5] has revealed convincing indications that sustainable businesses share a mental model or a "vision" widely shared throughout their organizational culture to respond to uncertainties effectively. Their organizational members embrace this shared future picture to guide their daily decision-making, which is particularly crucial when tradeoffs among goals are needed.

An organizational vision appears to have a significant role in business success as businesses with a well-communicated vision can over time attain and maintain sustained competitive advantages over those without such a vision [6]. While (a) vision, as a core element of a strong corporate culture [7], is regarded as necessary in ascertaining corporate sustainability, and (b) an appropriate vision can provide impetus for the future by mobilizing organizational members toward attaining it [8], scanty reported research, if any, has examined vision characteristics that are supportive of corporate sustainability [6], which is therefore our motivation for the present study.

Given the limited empirical support for sustainability visions in the literature, the main objective of the present study is to empirically identify characteristics of organizational visions that support corporate sustainability. Our research questions are as follows: 
1. What are the characteristics of an organizational vision that promote sustainability performance?

2. How does such a vision lead to corporate sustainability?

The following sections are organized as follows: background literature, methodology, analysis results and discussions, practical implications and conclusions.

\section{Background Literature}

In the following subsections, we introduce a sustainability vision theory, vision realization factors, and staff satisfaction as a proxy for corporate sustainability performance.

\subsection{Sustainability Vision}

A strong, productive culture always starts with a vision statement [9]. When a vision statement is genuine and simply displayed prominently, it can assist in orienting stakeholders [9] toward achieving the vision. Conveying enduring values and a lasting higher-order purpose [10], a "vision" is indeed a corporate pitch to guide employees and all other stakeholders to what is really meaningful to them [11] in their path toward realizing the vision. In doing so, corporate sustainability strategies should be formulated according to the vision [12]. Certainly, the strategic focus is on maximizing values to a wide range of stakeholders. A vision statement as a leadership tool reflects a clear indication whether organizational leaders care about strategic sustainability. Indeed, ensuring corporate sustainability requires an integration of the two dimensions of society and environment into the vision, culture and operations, which suggests a large-scale transformation is needed, [13] as these two dimensions are not often taken into account in organizational visions [14].

Two types of visions exist: positive and negative visions. Positive ones are inspiring, full of desirable, and often sustainable, values [3,15]. They adopt a transparent approach in reaching a more desirable future [15]. Clearly, they are more effective than negative ones, which have no passionate appeal [16]. Therefore, positive visions are capable of spurring change. In the sustainability context, positive visions are the ones conducive to corporate sustainability. They promote continuous development, as is required to survive in this rapidly changing world. On the other hand, negative visions are ones that direct energy to prevention, rather than innovation, signals that organizational members pull together solely when threatened, and are very short-term [15]. They are detrimental to corporate sustainability and limit corporate prosperity. Unfortunately, positive visions are less frequently found in the corporate world than negative ones.

For decades, an organizational vision has been emphasized as critical to leadership, strategy and sustainability [6]. However, vision is still not commonly defined, and is often confused with an organization's philosophy, mission, strategy and goals [6]. To avoid greater confusion, we define vision in the present study as a leader's individual cognitive concept used to guide his/her behaviors, options and actions [17]. In theory, Sustainability Visions have two components [6]: attributes and content.

\subsubsection{Vision Attributes}

Seven attributes for effective Sustainability Visions exist [6]: brevity, clarity, abstractness, challenge, future orientation, stability, and desirability or ability to inspire. They are theorized to facilitate the vision sharing process in an organization as discussed one by one below.

Vision brevity means a vision statement that contains approximately 11-22 words [6]. With the other six attributes, sustainability visions with such a length increase the chance of improved corporate sustainability, since a leader can articulate a brief sustainability vision frequently and continuously, and organizational members can then grasp it more easily. Consequently, organizational members can be more effectively guided by the sustainability vision in terms of their daily decisions, improving their own satisfaction and that of stakeholders. 
Clarity means a vision statement that directs at an overarching goal it wants to achieve [6]. With the other six attributes, such clear sustainability visions increase the chance of improved corporate sustainability, since organizational members realize precisely what their organization wants to achieve. Thus, clear sustainability visions direct the full energies of organizational members toward satisfying stakeholders.

Vision abstractness means a vision statement that is not a one-time, specific goal that can be achieved, then abandoned [6]. With the other six attributes, such abstract sustainability visions increase the chance of improved corporate sustainability, since abstractness allows members of the organization to feel a greater sense of a longer-lasting organization, and promotes self-governing and individually innovative interpretations among them in working toward satisfying stakeholders.

A vision challenge means a vision statement that challenges organizational members to continue contributing their best efforts toward delivering desirable sustainability outcomes [6]. With the other six attributes, such challenging sustainability visions increase the chance of improved corporate sustainability, since the more there is a discrepancy between its present reality and the sustainability vision, the more motivated organizational members are to work toward satisfying stakeholders.

A vision's future orientation means a vision statement that indicates the long-term organizational perspective [6]. With the other six attributes, such sustainability visions increase the chance of improved corporate sustainability, since the long-term, future organizational perspective permits a balance between long-term and short-term strategy formulations, and prudent management at all organizational levels attracts organizational commitment toward satisfying stakeholders, and draws members of the organization to work toward satisfying the stakeholders.

Vision stability means a vision statement that is less likely to be affected by environmental change [6]. With the other six attributes, such sustainability visions increase the chance of improved corporate sustainability, since a stable sustainability vision does not confuse organizational members particularly when they are implementing sustainability strategies, suggests leadership integrity, and promotes the incorporation of sustainability into daily operations among organizational members.

Vision desirability or a vision's ability to inspire means a vision statement that declares a goal which inspires organizational members [6]. With the other six attributes, such sustainability visions increase the chance of improved corporate sustainability, since members of the organization are drawn to working toward satisfying stakeholders by a desirable or inspiring sustainability vision.

\subsubsection{Vision Content}

Vision attributes alone are not going to make an impact. A vision needs to have meaningful and effective content to demonstrate and clarify the focal values which combine to create a desired manifestation of its direction, alongside reasonable recommendations for achieving the highly challenging goals associated with the vision [18-20]. As a matter of fact, vision content essentially defines organizational identity [18-20].

Specifically, vision content refers to an image of the collective future, the information embedded in the vision [21]. In the sustainable organization setting, the information or the image is frequently about such virtues as perseverance, ethics and integrity, social responsibility, and social innovation [6]. Gleaning the needs and desires of stakeholders, surpassing their differences, and appealing to a wide range of stakeholders to share mutual concerns toward the future or their organization, a sustainability vision widens the support base for implementing the vision [8] by allowing members of the organization to reflect on the needs and aspirations of a range of stakeholders, enhancing their own satisfaction and that of stakeholders [6].

Therefore, sustainability vision content is theorized to contain an imagery about improving the satisfaction of stakeholders, because they are vital to sustainable organizational success [6], and empirically, the imageries of improving venture growth, and customer 
and staff satisfaction were found to improve venture growth, and customer and staff satisfaction [22,23]. In essence, visions that seem desirable to organizational members are ones that associate possibilities and growth with sustainability values such as social responsibility [6]. Therefore, the more imagery about improving stakeholder satisfaction contained in a vision, the higher the satisfaction of organizational members, the higher the improvement in corporate sustainability.

Based on the literature, vision content in this study are imageries about improving sales, store leadership, and staff and customer satisfaction, as (a) sales represent the interests of staff, store managers and owners, (b) store leadership and staff satisfaction represent the interest of staff, store managers and owners, and (c) customer satisfaction represents the interest of customers, staff, store managers and owners. All of these are corporate stakeholders, which is consistent with the Sustainability Vision theory [6]. More importantly, staff have an interest in all these imageries. Thus, we use staff satisfaction as the proxy for corporate sustainability, which will be discussed in the following Staff Satisfaction section.

In summary, the sustainability vision content of sales, store leadership, and staff and customer satisfaction imageries that represent stakeholder interests, and the seven sustainability vision attributes of brevity, clarity, abstractness, challenge, future orientation, stability, and desirability or ability to inspire facilitate a sustainability vision's communication, articulation and sharing processes. With the resulting shared sustainability vision, organizational members become committed emotionally to the sustainability vision by wanting to improve stakeholder satisfaction, thereby increasing their own satisfaction and sustainability performance.

\subsection{Vision Realization Variables}

Simply having a vision will not lead to sustainable success, as vision alone contributes to only 10 percent of organizational success [24]. Vision realization factors are needed. Each vision realization factor is discussed below.

As part of forming a strong organizational culture, vision communication has long been regarded as key to the successful implementation of a vision [3,25]. Organizational leaders and managers communicate their organizational visions in a variety of ways, such as through written statements and personal communication [26,27]. In particular, as an organization is growing, vision communication, articulation and sharing processes among organizational members is necessary so that all members share the same vision [28]. Such a shared vision allows members to become self-adapting in response to the changing environment [28], allowing the organization to find a way to survive and thrive in the increasingly dynamic world.

Vision Communication is operationally defined as the extent to which a sustainability vision is communicated by a store manager via spoken, written and/or technologymediated channels.

After communicating the vision, organizational members start to share and intrinsically want to turn the vision into reality. The existing organizational systems may not be supportive to them. Therefore, the systems need to be aligned with the sustainability vision. These organizational systems range from organizational structures and processes, organizational culture, recruiting systems, incentives and job design [29,30]. Effective sustainability visions also align people in an organization, freeing energies that might have been consumed by irrelevant matters among them toward the attainment of the vision [31]. As a matter of fact, the entire organizational alignment process can be defined as leadership [32]. Empirically, in retail stores, store managers who do not align organizational systems with their store vision frustrate their staff members because the unsupported organizational systems will become obstacles whenever they are intended to realize the vision [30]. 
Organizational Alignment is in the present study operationally defined as the extent to which a store manager developed new staff performance evaluation criteria according to the vision, and reassigned his/her staff as needed to support his/her vision.

While an alignment of organizational systems to suit a vision concerns structural changes, empowerment entails delegating and giving out power to organizational members no matter where they are in the organizational levels [33]. Organizational members are allowed a reasonable degree of independence to decide and commit to do something supportive to the vision [34]. Specifically, sustainable enterprises promote self-governing teams where employees are fully empowered in their operations [26]. In doing so, a shared vision is used as part of a soft organizational control [3] for the self-governing teams. With such empowerment, organizational members feel involved with the vision and are allowed some room to individually, innovatively interpret the sustainability vision as they feel relevant to their work [35]. It is not surprising that sustainable corporations are found to have innovation as a core value and are highly innovative [3,26]. Sharing the sustainability vision, empowered organizational members can use the sustainability vision to promptly inform their judgements and actions [6]. Such timely judgements and actions are highly suitable for the non-linear, complex and non-static nature of the present corporate environment.

Empowerment of Staff is operationally defined as the extent to which a staff member felt involved with his/her store manager's vision, and a store manager delegated work to staff, provided support services and resources to staff, and encouraged staff to make more decisions regarding daily store operations.

Sustainable enterprises focus on intrinsic motivation among organizational members. They usually have a highly motivated group of employees [1,26]. Vision-guided leaders espouse their vision to arouse organizational members to work toward their vision, especially in difficult times [36]. Essentially, a vision can be a leadership tool to motivate organizational members, develop long-term commitments among them, and enable the organization to adapt over time [37]. Motivation also increases when organizational members see their leader is passionate about his/her vision [8], meet their leader's high expectations, and, through such a process, enhance their perceived self-efficacy, which is an important foundation of motivation [38]. Motivation also comes from decisions they are allowed to make, and from job designs and sound judgements on rewards and compensation $[39,40]$. In addition, as challenges are a form of motivation, a challenging vision allows organizational members to increase their own esteem while trying to attain the vision [41]. In such a process, organizational members are motivated and satisfied [42].

Motivation of Staff is operationally defined in the present study as the extent to which a staff member was committed to his/her store manager's vision, and a store manager acted as a role model for staff, was passionate about his/her vision, built staff's selfconfidence, challenged staff, and rewarded staff who exhibited consistent behaviors with his/her vision.

\subsection{Staff Satisfaction}

Throughout the entire corporate sustainability literature, keeping organizational members satisfied [1,3] is clear, as they are the drivers toward corporate sustainability [3,26]. Empirically, sustainable organizations give their organizational members priority $[3,26]$. They make sure that their organizational members are secured, highly motivated and satisfied with their jobs so that they can push sustainability forward.

The satisfaction of organizational members is indeed a positive state of mind caused by both intrinsic and extrinsic job elements [43]. Intrinsic satisfaction refers to satisfaction toward the job tasks themselves, including skill utilization, autonomy [44], recognition, and responsibility, or the growth and self-actualization of the organizational members [45], while extrinsic satisfaction refers to satisfaction irrelevant to job tasks or work content (e.g., pay, working conditions, and colleagues) [46]. Once organizational members are satisfied with their jobs, they are more likely to develop a more positive self-concept at work and 
stronger self-determination, which facilitates higher efficiency [47] and better service [48] to work toward the sustainability vision, resulting in improved sales, store leadership positions, and customer satisfaction. In such a process, the corporate sustainability prospect is enhanced.

Staff Satisfaction is operationally defined in the present study as the extent to which a staff member was satisfied with task requirements, autonomy, colleagues, interactions, pay, fringe benefits, recognition, professional status, staff policies, guidance, and career advancement [49].

\section{Methodology}

This section explains the design of the methodology used to answer the two research questions: (1) What are the characteristics of an organizational vision that promote sustainability performance? and (2) How does such a vision lead to corporate sustainability?

To answer the research questions, the present study adopts the positivistic paradigm of research because it is required to generate explanatory, causal relationships between vision characteristics and sustainability performance [50], which is not possible under the phenomenological paradigm of research. The key characteristic of the positivistic paradigm is to isolate and control the influence of all factors so that only the observed variables of interest are examined [51]. In our case, we want to determine if certain vision characteristics could have caused improved prospects of sustainability performance. Our focus is thus to design and gather evidence to support our hypothesized, causal inference. In doing so, we adopt the quantitative research methods that focus on objective measurements and the statistical analysis of data collected through questionnaires [50], details of which are explained in this section.

We start by discussing how we derived our model and its hypotheses, both of which are related to the characteristics of a sustainability organizational vision and how it is realized to improve corporate sustainability performance. Then, we continue by introducing our data analysis approach.

\subsection{Model Development}

This subsection explains how we derived a final model and hypotheses for subsequent analysis. We started by developing a conceptual model from the literature, testing its construct validity and reliability, and eventually developing a structural model and hypotheses for our subsequent data analysis.

\subsubsection{Conceptual Model Development}

Based on the literature review above, Figure 1 below shows an initial conceptual model expressing relationships derived from the literature.

This conceptual model is used to develop two sets of questionnaire for store managers and staff members. After we collected the data, we tested the model's construct validity and reliability. We explain next our data collection process, the methods used to test the construct validity and reliability, and how we derived a structural model and its hypotheses.

\subsubsection{Structural Model Development}

To test the construct validity and reliability of the conceptual model, a sample was drawn from retail stores selling food, consumer, and health products located in the Bangkok Metropolitan Region's shopping malls. Forty major shopping malls throughout the Bangkok Metropolitan Region were approached. Thirty-three shopping malls are located in Bangkok in a distributed way, while the other 7 major malls are in the 3 vicinity areas-Nonthaburi, Samut Prakan, and Pathum Thani. The non-probability sampling schemes were applied [52]. In total, 180 stores were approached, with 169 participating stores. Out of 169 stores, 139 stores are located in Bangkok, while 30 stores are in the vicinity areas. 


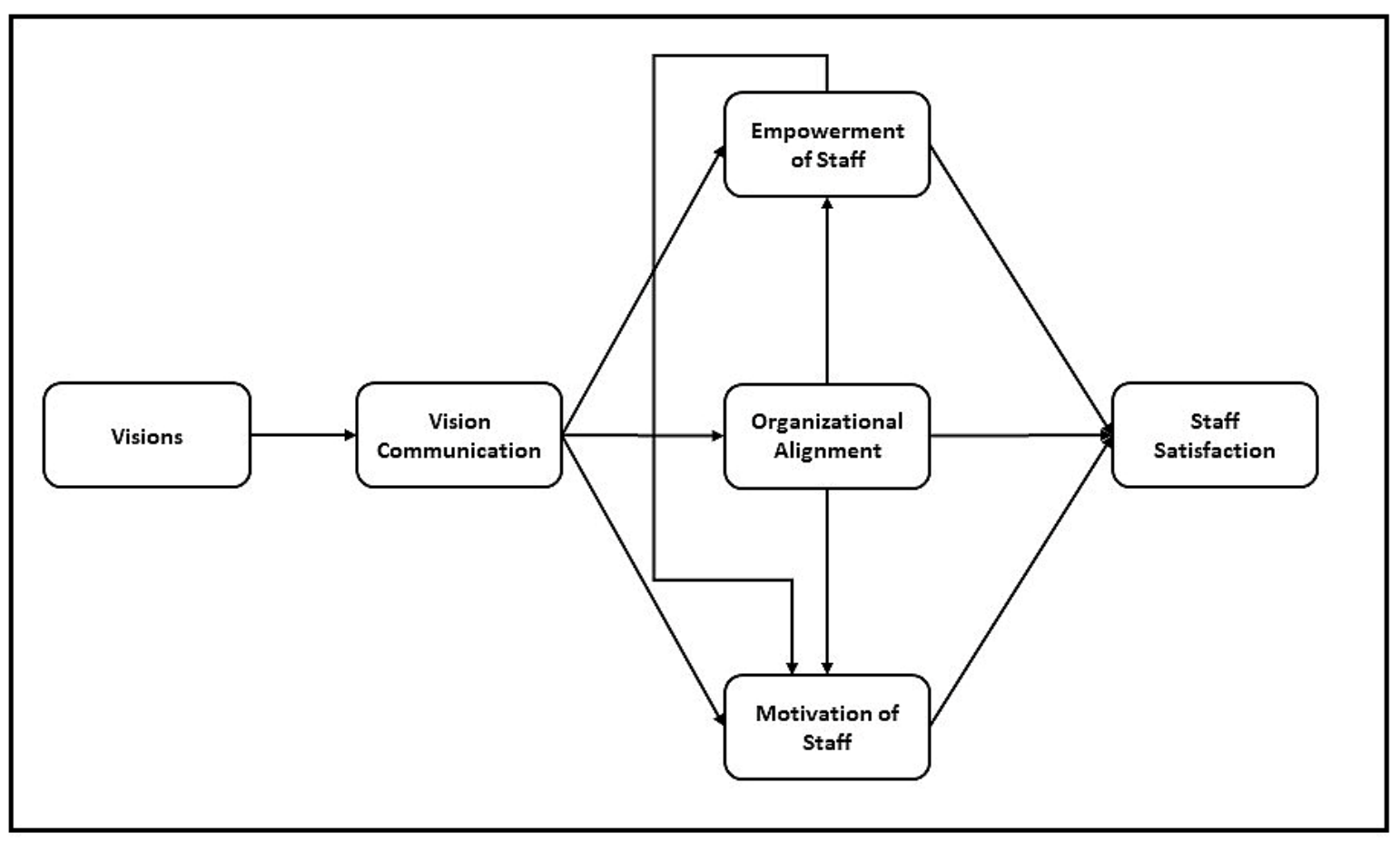

Figure 1. A conceptual model showing literature-derived relationships among sustainability visions, vision realization variables, and staff satisfaction.

Store managers are full-time store employees who are stationed at the stores daily to manage their own stores. Staff members are full-time, part-time and casual employees who work under the supervision of store managers. A total of 169 store managers and 721 staff members were surveyed. At each store, around 3 to 5 staff members were surveyed, depending on their availability.

To develop the store manager and staff questionnaires, the Vision Communication, Motivation of Staff, Empowerment of Staff, Organizational Alignment, and Staff Satisfaction constructs were operationalized into relevant measured items, based on the literature review above. A nine-point ordinal scale was adopted to measure all domains in Figure 1, except Sustainability Vision, for which we used a five-point ordinal scale, following previous studies $[53,54]$. We used the ordinal scale because it is appropriate to depict nonmathematical ideas such as job attitude satisfaction, happiness, and frequency [55].

All scales were measured on a self-reported basis, because we wanted the staff respondents to report retrospective behaviors of their store managers and their own satisfaction [56]. Similarly, we also wanted the store manager respondents to report on their own leadership behaviors. We took the following steps while approaching the respondents to reduce social desirability bias, which is a critical issue in conducting research with self-reports, because respondents tend to answer questions in a manner that will be viewed favorably by others [57].

First, a researcher asked the store manager if he/she would agree to participate in the study, and give permission to approach his/her staff. The response rate for store managers was $93.8 \%$. Next, a staff member was first informed that his/her responses would be kept confidential. The researcher then asked the staff member if he/she agreed to participate in the study. If he/she agreed, he/she would be accompanied out of the store to fill in the questionnaire. After the first staff member, the researcher approached the next staff member until three staff questionnaires were filled, unless it was not possible to finish the three staff questionnaires. The response rate for staff was $85 \%$.

The store manager questionnaire collected demographic and sustainability vision data. Store managers were asked if they had a vision for their store. If yes, he/she was asked to write down his/her vision. The store managers were also asked to indicate the extent from 
one (never) to nine (always) to which they behaved consistently with the Organizational Alignment measured items.

The staff questionnaire contains measured items for vision desirability and challenge attributes, Motivation of Staff, Empowerment of Staff, and Staff Satisfaction. Addressing prior studies' limitations [53,54], the researcher wrote down the self-written store manager's vision statement on the staff questionnaire before asking staff to respond to the question items measuring the two vision attributes of challenges and desirability or the ability to inspire. This was to make sure that there was an alignment between the store manager's vision and the staff's store vision. Out of 169 stores, 144 store managers reported having a vision for their stores, while 25 store managers reported having no vision. These 25 stores were assigned zero for both vision attributes and content.

After reading their store manager's vision statement, staff were responsible for indicating the extent, from one (absence) to five (strong presence), to which they think their store vision was challenging and desirable or had an ability to inspire on a five-point Likert scale. In addition, staff were also asked to indicate the extent, from one (never) to nine (always), to which their store manager acted consistently with the measured items of Vision Communication, Motivation of Staff, and Empowerment of Staff. Staff were also asked to respond to the measured items for Staff Satisfaction.

In the present study, procedural methods [58] were adopted to minimize the risk of common method variance, as it may bias the empirical findings from a study that uses respondents or raters as data sources [59]. Common method variance is systematic error variance shared among variables measured with and introduced as a function of the same method and/or source [60]. A tendency of respondents to indicate the same answers across items is a well-known example.

First, we informed all respondents that the anonymity and confidentiality of their responses were guaranteed, and there were no right or wrong answers. In addition, the ordering of multiple items was random in our questionnaires, verbal designations for the midpoints of the scales were not assigned, and bipolar numerical values were not adopted.

Vision prototypes [53] (p. 51) were adapted, as shown in Table 1, to rate the remaining five attributes and content of the sample vision statements. The vision rating, using a fivepoint ordinal scale ranging from one (absence of the attributes and content) to five (strong presence of the attributes and content), was performed by two independent researchers who were trained on vision rating. The two researchers debated until a consensus was reached when contradicting views existed. The inter-rater reliability was also acceptable [61].

A factor analysis was conducted to identify relevant measured items for the domain constructs [62]. The domain constructs and resulting measured items are shown in Table 2 below.

To ensure sufficient construct validity, meaning that the measured items were representative of each domain variable, two criteria were used. First, loading values needed to be considered. Pathak, Singh and Badhotiya [63] advise that researchers should consider loading values lesser than 0.32 to be poor, 0.45 to be fair, 0.55 to be good, 0.63 to be very good, and 0.71 to be excellent. Furthermore, loading values exceeding 0.40 are considered acceptable and represent a good loading value [64]. In our present study, we adopt a loading value of more than 0.5 as an acceptable loading value. Second, they should only be loaded on the extracted domain variable [62]. Items that cross-loaded on two domain variables were dropped from each construct.

Based on the criteria, spoken communication was dropped from the Vision Communication construct since its loading value was below 0.4. Two items of Empowerment of Staff were removed for the same reason. Some Motivation of Staff items were eliminated or combined with the Empowerment of Staff construct as they either had a loading value below 0.4 or more correlated with the Empowerment of Staff measured items than the Motivation of Staff measured items. Staff Satisfaction items were reduced to four items, given that the rest did not have high enough loading values. 
Table 1. Vision prototypes. Adapted from [53] (p. 51).

\begin{tabular}{|c|c|c|c|c|c|c|c|c|c|c|}
\hline \multirow[b]{2}{*}{ No. } & \multirow[b]{2}{*}{ Vision Prototype } & \multicolumn{5}{|c|}{ Vision Attribute } & \multicolumn{4}{|c|}{ Vision Content of Stakeholder Satisfaction Imagery } \\
\hline & & Brief & Clear & Abstract & $\begin{array}{c}\text { Future } \\
\text { Oriented }\end{array}$ & Stable & Sales & $\begin{array}{c}\text { Store } \\
\text { Leadership }\end{array}$ & $\begin{array}{c}\text { Staff } \\
\text { Satisfaction }\end{array}$ & $\begin{array}{c}\text { Customer } \\
\text { Satisfaction }\end{array}$ \\
\hline 1 & $\begin{array}{l}\text { We want to become the best } \\
\text { socially responsible store in } \\
\text { Thailand via } \\
\text { satisfying stakeholders. }\end{array}$ & 5 & 5 & 5 & 5 & 5 & 5 & 5 & 5 & 5 \\
\hline 2 & $\begin{array}{l}\text { We want to be a store that } \\
\text { people are proud of and } \\
\text { committed to, where all } \\
\text { employees have an } \\
\text { opportunity to contribute, } \\
\text { learn, grow, and advance } \\
\text { based on merit, not politics or } \\
\text { background. We want our } \\
\text { people to feel respected, } \\
\text { treated fairly, listened to, and } \\
\text { involved. Above all, we want } \\
\text { to build on the foundations } \\
\text { that we have inherited, affirm } \\
\text { the best of our traditions, } \\
\text { closing gaps that may exist } \\
\text { between principles and } \\
\text { practices, and updating some } \\
\text { of our values to reflect } \\
\text { contemporary circumstances. }\end{array}$ & 0 & 1 & 3 & 1 & 2 & 2 & 2 & 5 & 2 \\
\hline 3 & $\begin{array}{l}\text { We want to be recognized for } \\
\text { high professionalism and } \\
\text { consumerism in headlines of } \\
\text { the Thai Retailer Association } \\
\text { newsletter for providing the } \\
\text { best quality } \\
\text { products/services and } \\
\text { customer satisfaction } \\
\text { in Bangkok. }\end{array}$ & 4 & 5 & 3 & 5 & 4 & 3 & 4 & 3 & 5 \\
\hline 4 & $\begin{array}{l}\text { We want to be recognized for } \\
\text { developing Thailand's most } \\
\text { highly skilled retail workforce } \\
\text { through team self-selection } \\
\text { and self-mentoring } \\
\text { of apprentices. }\end{array}$ & 5 & 4 & 3 & 4 & 4 & 1 & 3 & 5 & 1 \\
\hline 5 & $\begin{array}{l}\text { We want to double our } \\
\text { customer satisfaction rate in } \\
\text { two years. }\end{array}$ & 5 & 5 & 2 & 1 & 1 & 1 & 1 & 1 & 5 \\
\hline
\end{tabular}

Table 2. Domain constructs and their measured items.

\begin{tabular}{cc}
\hline Domain Construct & Measured Items \\
\hline Visions & Vision attributes \\
\hline & Vision content \\
\hline Vision Communication & Written communication \\
\hline Empowerment of Staff & Staff commitment to the vision \\
\hline & Store manager acting as a role model \\
\hline & Store manager building staff self-confidence \\
\hline Motivation of Staff & Store manager challenging staff to do their job better \\
\hline & Store manager delegating tasks to staff \\
\hline Staff Satisfaction & Store manager passion for vision \\
\hline & Store manager rewarding staff \\
\hline & Pay \\
\hline & Perception of others as a retail professional \\
\hline
\end{tabular}


Finally, all constructs had a Cronbach's alpha greater than 0.50, an acceptable value [65]. The results show measurement scales comprising a set of homogeneous measured items to ensure the intended meaning of each construct. Therefore, we combined the rated scores to form each of the five domain constructs with a Kaiser-Meyer-Olkin (KMO) value of 0.958 . Accordingly, construct validity for the model was sufficiently present after all adjustments and combinations [62].

In terms of scale reliability, the Organizational Alignment construct was removed from the conceptual construct and the subsequent analyses due to a low Cronbach's alpha value of only 0.383 . Apart from that, the results yielded values ranging from 0.583 to 0.926 , which are greater than 0.5 , an acceptable value for reliability [65]. Details are shown in Table 3 below.

Table 3. Construct reliability.

\begin{tabular}{cccc}
\hline No. & Construct & Cronbach's Alpha & No. of Measured Items \\
\hline 1 & Visions & 0.583 & 11 \\
2 & Vision Communication & 0.799 & 2 \\
3 & Empowerment & 0.926 & 6 \\
4 & Motivation & 0.635 & 2 \\
5 & Staff Satisfaction & 0.808 & 4 \\
\hline
\end{tabular}

Accordingly, the following structural model and its hypotheses are derived for analyses as shown in Figure 2 below.

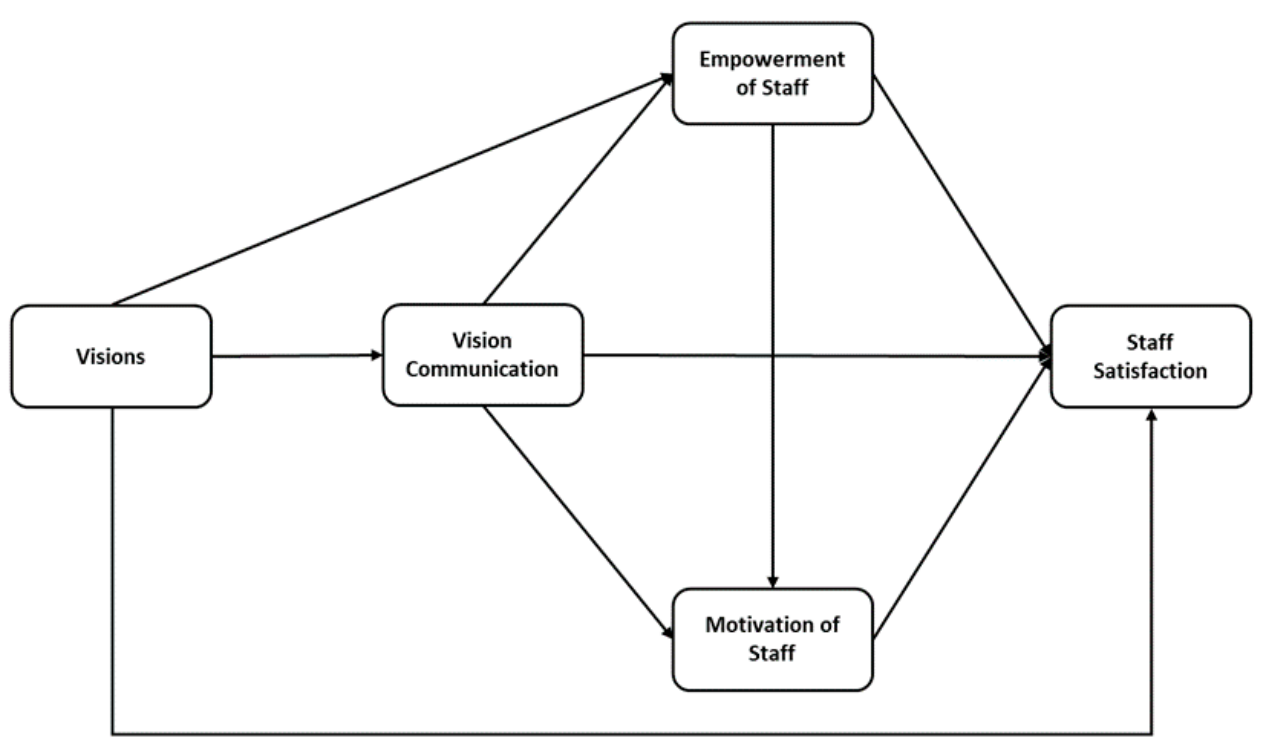

Figure 2. Structural model showing hypothesized relationships among visions, Vision Communication, Motivation of Staff and Empowerment of Staff, and Staff Satisfaction.

From left to right, Sustainability Visions characterized by the seven attributes and content directly improve Staff Satisfaction and Vision Communication by store managers. The Sustainability Visions also improve Empowerment of Staff and Motivation of Staff directly, since store managers have a prime goal in their minds to empower and motivate staff. Vision Communication directly improves the level of Staff Satisfaction and allows store managers to more effectively empower and motivate their staff. Concurrently, Empowerment of Staff also leads to improvement in Motivation of Staff. Both Motivation of Staff and Empowerment of Staff lead to a higher level of Staff Satisfaction. Accordingly, the following directional hypotheses were derived for testing. 
Hypothesis 1 (H1). Sustainability Visions are directly predictive of enhanced Vision Communication.

Hypothesis 2 (H2). Vision Communication is directly predictive of enhanced Staff Satisfaction.

Hypothesis 3 (H3). Vision Communication is directly predictive of enhanced Motivation of Staff.

Hypothesis $4 \mathbf{( H 4 ) . ~ V i s i o n ~ C o m m u n i c a t i o n ~ i s ~ d i r e c t l y ~ p r e d i c t i v e ~ o f ~ e n h a n c e d ~ E m p o w e r m e n t ~}$ of Staff.

Hypothesis 5 (H5). Empowerment of Staff is directly predictive of enhanced Staff Satisfaction.

Hypothesis 6 (H6). Motivation of Staff is directly predictive of enhanced Staff Satisfaction.

Hypothesis 7 (H7). Empowerment of Staff is directly predictive of enhanced Motivation of Staff.

Hypothesis $\mathbf{8}$ (H8). Sustainability Visions are directly predictive of enhanced Staff Satisfaction.

Hypothesis 9 (H9). Sustainability Visions are directly predictive of enhanced Empowerment of Staff.

\subsection{Data Analysis Approach}

This subsection explains our approach to testing the structural model and its hypotheses. Given the nature of the sophisticated structural model with multiple layers, the Structural Equation Modelling (SEM) technique is determined to be appropriate to analyze the aggregated data [62] at the store unit of analysis. We adopted the multi-level Structural Equation Model (MLSEM) using MPlus to control for store-level effects. The complete SEM model consists of two steps [62]: the Measurement Model and the Structural Model. The Structural Model assesses the Overall Fit of the Model, while the Measurement Model or Confirmatory Factor Analysis (CFA) represents how measured variables come together to represent the domain constructs.

In terms of determining an appropriate sample size for the SEM, there is much ongoing debate in the literature, with no commonly agreed approach. Therefore, we apply several criteria to determine a minimum sample size for the present study.

Our sample size of 169 stores meets the following criteria. First, the most popular method of '10-times rule' [66] states that the sample size should be 10 times greater than the latent variables in the model. Given this study had five latent variables, only 50 sample stores were required. Second, there is a general rule of thumb, as suggested by Hair et al. [67], Kline [68] and Wang and Wang [69], that 100 samples are the practical minimum size for using the SEM. Third, according to Pallant [70], the sample size should be at least five times larger than the number of measured items. With 25 measured items, this study requires 125 as the minimum sample size. Finally, Hair et al. [67] also suggest that when a model contains seven or fewer constructs with modest communalities $(0.5)$, the minimum sample size should be 150 . In the present study, the model had five constructs, and the minimum communality value used to determine the inclusion of all measured items in the model was 0.5 .

Therefore, our sample size of 169 stores meets the four criteria, as suggested by Hair et al. [67], Hair et al. [66], Kline [68], Wang and Wang [69], and Pallant [70]. We present and discuss the analysis results in the next section.

\section{Analysis Results and Discussions}

Based on our analysis, the Measurement Model (Figure 3) demonstrates that all measures have an acceptable Goodness of Fit, as shown in Table 4 . In addition, there are no common method variance issues. 


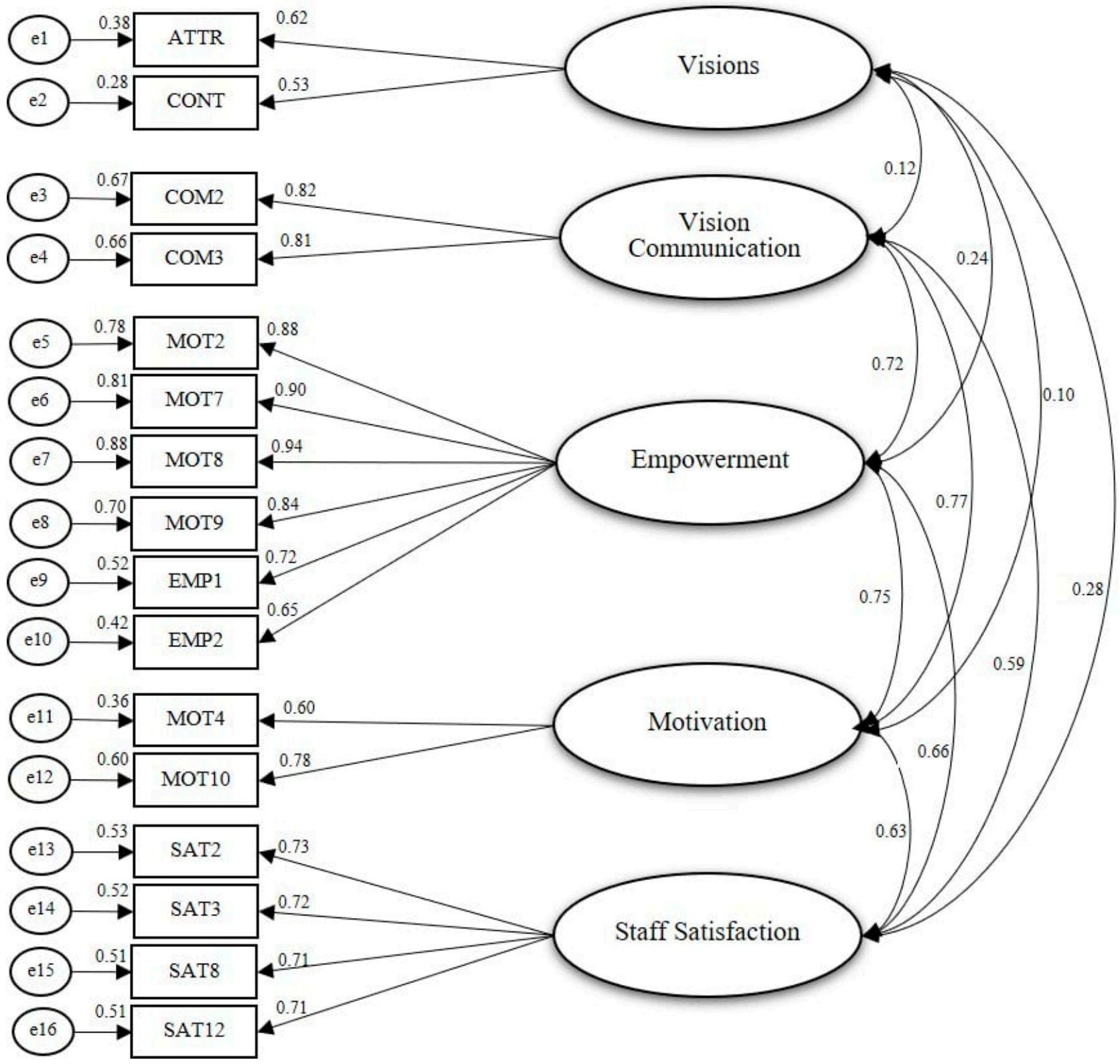

Figure 3. The Measurement Model.

Table 4. Goodness of Fit measures.

\begin{tabular}{cccc}
\hline Measurements & Required Values & References & Achieved Values \\
\hline CMIN/DF & $<5.0$ & Marsh \& Hocevar [71] & 3.84 \\
GFI & $>0.90$ & Hair et al. [67] & 0.931 \\
AGFI & $>0.90$ & Hair et al. [67] & 0.903 \\
CFI & $>0.90$ & Hair et al. [62] & 0.95 \\
RMSEA & $<0.08$ & Hair et al. [67] & 0.068 \\
\hline
\end{tabular}

In the same manner, the resulting Structural Model reveals an Overall Fit with CMIN/DF $=3.856$, Goodness-of-Fit Index $(\mathrm{GFI})=0.931$, Adjusted Goodness-of-Fit In$\operatorname{dex}(\mathrm{AGFI})=0.903$, Comparative Fit Index $(\mathrm{CFI})$ value $=0.950$, and Root Mean Square Error Approximation $($ RMSEA) $=0.068$ (as seen in Figure 4), suggesting the theorized hypotheses and collected data are consistent. 


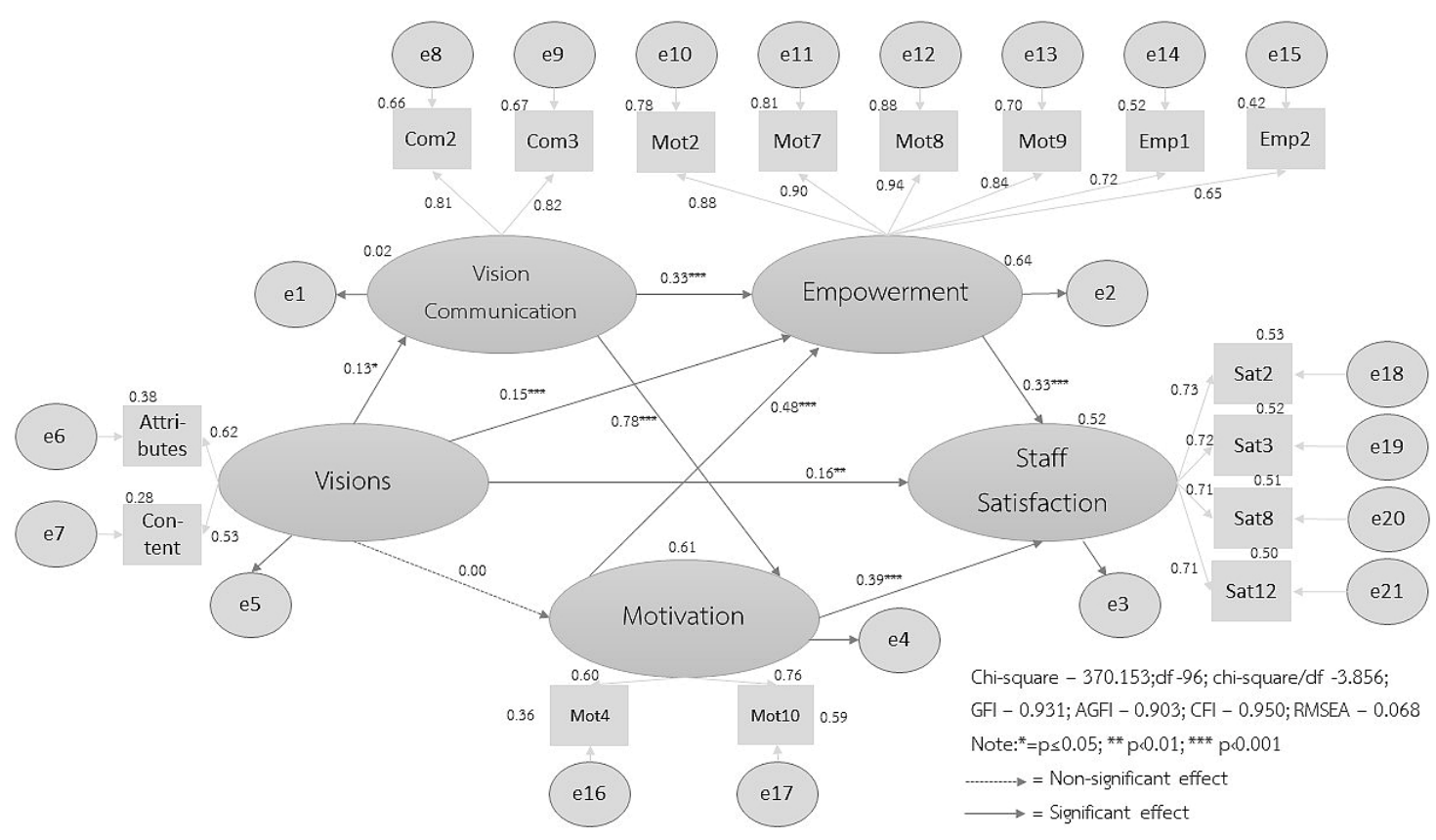

Figure 4. The Structural Model indicating the relationships between Sustainability Visions, Vision Communication, Empowerment of Staff, Motivation of Staff and Staff Satisfaction.

A summary of direct, indirect and total effects is shown in Table 5 below.

Table 5. Effect values.

\begin{tabular}{ccccc}
\hline \multirow{2}{*}{ Causal Variables } & Effect Variables & \multicolumn{3}{c}{ Effect Types $(\beta)$} \\
\cline { 3 - 5 } & & DE & IE & TE \\
\hline Visions & Vision communication & $0.126^{*}$ & - & $0.126^{*}$ \\
Visions & Motivation & 0.002 & - & 0.002 \\
Vision communication & Motivation & $0.782^{* * *}$ & - & $0.782^{* * *}$ \\
Vision communication & Empowerment & $0.333^{* * *}$ & - & $0.333^{* * *}$ \\
Visions & Empowerment & $0.148^{* *}$ & - & $0.148^{* * *}$ \\
Motivation & Empowerment & $0.478^{* * *}$ & - & $0.478^{* * *}$ \\
Empowerment & Staff satisfaction & $0.328^{* * *}$ & - & $0.328^{* * *}$ \\
Motivation & Staff satisfaction & $0.391^{* * *}$ & - & $0.391^{* * *}$ \\
Visions & Staff satisfaction & $0.160^{* *}$ & - & $0.160^{* *}$ \\
\hline Note $^{*}=p<0.05^{* *} p<0.01^{* * *} p<0.001 ;$ TE $=$ Total Effect; DE $=$ Direct Effect; IE $=$ Indirect Effect;
\end{tabular}
$\beta=$ Standardized Regression Coefficient.

Resulting casual-effect indirect relationships are also summarized in Table 6 below.

Table 6. Casual-effect indirect relationships.

\begin{tabular}{|c|c|c|c|}
\hline \multirow{2}{*}{ Casual-Effect Indirect Relationships } & \multicolumn{3}{|c|}{ Effect Types $(\beta)$} \\
\hline & DE & IE & TE \\
\hline \multirow{4}{*}{$\begin{array}{c}\text { Vision }>\text { Vision communication }>\text { Empowerment }> \\
\text { Staff satisfaction } \\
\text { Vision }>\text { Vision communication }>\text { Motivation }> \\
\text { Staff satisfaction } \\
\text { Vision }>\text { Vision communication }>\text { Motivation }> \\
\text { Empowerment }>\text { Staff satisfaction } \\
\text { Vision }>\text { Empowerment }>\text { Staff satisfaction }\end{array}$} & \multirow{4}{*}{$0.160 * *$} & 0.014 & \multirow{4}{*}{0.276} \\
\hline & & 0.039 & \\
\hline & & 0.015 & \\
\hline & & 0.049 & \\
\hline & $0.160^{* *}$ & 0.116 & 0.276 \\
\hline
\end{tabular}


Based on the analysis results, we tested our hypotheses. Our findings indicate that Sustainability Visions directly predict improvements in Vision Communication. Therefore, $\mathrm{H} 1$ is supported. Our findings also reveal that Vision Communication directly predicts improvements in Empowerment of Staff and Motivation of Staff. Therefore, H3 and H4 are supported. However, Vision Communication does not directly predict improvements in Staff Satisfaction. As a result, H2 is not supported. Next, our findings disclose that Empowerment of Staff and Motivation of Staff directly predict improvements in Staff Satisfaction. Thus, H5 and H6 are supported. As for H7, our findings indicate that Empowerment of Staff does not directly predict improvements in Motivation of Staff. Therefore, H7 is not supported. Finally, our findings indicate that Sustainability Visions are directly predictive of improvements in Staff Satisfaction and Empowerment of Staff. A summary of our hypothesis testing results is shown in Table 7 below.

Table 7. Hypothesis testing results.

\begin{tabular}{ccc}
\hline Hypothesis & Supported & Not Supported \\
\hline H1: Sustainability Visions are directly predictive of enhanced Vision Communication. & $X$ & $X$ \\
H2: Vision Communication is directly predictive of enhanced Staff Satisfaction. & $X$ & $X$ \\
H3: Vision Communication is directly predictive of enhanced Motivation of Staff. & \\
H4: Vision Communication is directly predictive of enhanced Empowerment of Staff. & \\
H5: Empowerment of Staff is directly predictive of enhanced Staff Satisfaction & $X$ \\
H6: Motivation of Staff is directly predictive of enhanced Staff Satisfaction & $X$ \\
H7: Empowerment of Staff is directly predictive of enhanced Motivation of Staff & $X$ \\
H8: Sustainability Visions are directly predictive of enhanced Staff Satisfaction & $X$ \\
H9: Sustainability Visions are directly predictive of enhanced Empowerment of Staff & \\
\hline
\end{tabular}

Based on the analysis results, the Sustainability Vision theory [6] is endorsed as having a critical role in improving sustainability prospects via staff satisfaction, which is consistent with the broader literature indicating that sustainable companies espouse a "vision" or a mental model widely shared throughout their organization $[1,4,5,26]$. As part of the widely shared organizational culture, an organization can effectively deal with uncertainties [26]. An example set of vision statement samples is shown in Table 8 below.

Table 8. Examples of vision statement samples.

\begin{tabular}{|c|c|}
\hline Store No. & Sample Store Manager Vision Statements \\
\hline 1 & $\begin{array}{c}\text { Maintain the best quality in products, services, and store cleanliness to generate } \\
\text { customer satisfaction and repeated customers. }\end{array}$ \\
\hline 2 & $\begin{array}{l}\text { Lead the team to achieve the company's goals and be ready to accept changes, new } \\
\text { technologies and knowledge, and to make sure employee are satisfied. }\end{array}$ \\
\hline 3 & $\begin{array}{c}\text { We focus on being a quality organization by being a leader in Thailand's retail and } \\
\text { service industries. }\end{array}$ \\
\hline 4 & $\begin{array}{l}\text { Cultivate all employees with a service-minded attitude, honesty toward themselves } \\
\text { and colleagues. Be supportive to colleagues, help each other, and always be } \\
\text { customer-centric. }\end{array}$ \\
\hline 5 & $\begin{array}{l}\text { Be the best-selling branch that offers good services, quality products with } \\
\text { excellent functionality. }\end{array}$ \\
\hline
\end{tabular}

The present study reveals that Sustainability Visions directly predict improvements in Vision Communication. Since visions characterized by brevity, clarity, future orientation, stability, challenges, abstractness and ability to inspire, and which contain imageries about improving sales, store leadership, and customer and staff satisfaction really improve Vision Communication in the present study, the Sustainability Vision theory [6] has gained support, as it asserts that the seven vision attributes and the content of stakeholder satisfaction imagery facilitate the vision communication and sharing process. Brief, clear and stable visions lead to better Vision Communication, allowing store managers to communicate 
their visions more frequently and on a larger scale. Certainly, organizational members understand a brief vision message more quickly than a long one [72], because a brief vision message allows for the considerable, recurrent articulation and communication needed to turn a sustainability vision into reality $[73,74]$. Organizational members at all levels are required to receive sustainability vision messages as frequently as possible to help support the organization, so that initiatives on corporate sustainability are successfully carried out [6].

In addition, Sustainability Visions in theory are desirable or have an ability to inspire. Therefore, it is not surprising that Sustainability Visions in the present study directly improve Staff Satisfaction without Vision Communication effects, since the Visions themselves, containing imagery about improving staff satisfaction, are desirable or inspiring. Consistently, a vision statement alone can assist in orienting organizational members and stakeholders when it is genuine and prominently displayed [9]. Supporting this view is Senge [15], who asserts that positive visions are infused with desirable values, and are inspirational and translucent in their approach in achieving a better and desirable future [15]. Such visions are more effective than negative ones with no emotional appeal [16]. It must be noted that, although the direct effect from Sustainability Visions to Staff Satisfaction is significant, the co-efficient value is quite small $(\beta=0.16)$. This makes much sense, as it suggests that Sustainability Visions alone can make a direct impact on Staff Satisfaction in a small retail store setting. However, with the vision realization factors of Vision Communication, Motivation of Staff and Empowerment of Staff, the impact on Staff Satisfaction can be improved, which will be discussed below.

One may be questioning why Vision Communication does not create a direct impact on Staff Satisfaction in the present study. If we take a closer look at the measured items for Vision Communication, a possible answer can be provided, since they do not include spoken vision communication. Without speaking to staff about visions, it is unlikely that Vision Communication would directly create an impact on Staff Satisfaction, pending future research.

Another area for future research is about Stakeholder Satisfaction imagery. In the present study, we only take into consideration a limited number of stakeholders: store managers, owners, staff and customers. Sustainable enterprises take into consideration a broad range of stakeholders, including society and future generations [3]. Therefore, future research may consider including such stakeholders as the community in their vision content.

The finding that Sustainability Visions directly predict improvements in Empowerment of Staff also endorses the Sustainability Vision theory [6]. In terms of Empowerment of Staff, the theory asserts that abstractness in Sustainability Visions allows organizational members to interpret the visions in their own way and to suit their work, which is endorsed by scholars who state that visions guide members of an organization to focus on matters really relevant to them and their stakeholders [11] in their journey toward transforming vision ideas into actions.. In the present study, Empowerment of Staff includes staff commitment and involvement in their store manager's vision. We may draw from these measured items that staff with a high degree of involvement in and commitment to the store manager's vision might have used and interpreted the vision in their daily work, improving their own satisfaction in the process. Future research could explore this process further.

Based on the findings, Vision Communication directly predicts improvements in Empowerment of Staff and Motivation of Staff. This suggests written- and technologymediated vision communication allows staff to perceive store managers as acting as a role model, delegating tasks to them, and challenging them to do their jobs better and make them feel committed and involved with the store manager's vision. At the same time, such vision communication by store managers also leads to staff perceptions that their store managers are passionate about their vision and reward them according to their vision. In this process, staff members are satisfied and motivated, pending future qualitative research. 
The finding that Empowerment of Staff directly predicts improved Staff Satisfaction is understandable. The fact that store managers, with their vision in mind, are perceived by staff to effectively delegate work to staff, act as a role model, build staff self-confidence, and challenge them to do their jobs better, certainly helps to improve their satisfaction, as measured by pay, fringe benefits, perception by others as a retail professional, and career advancement opportunities. Staff involvement and commitment as part of Empowerment of Staff in the present study also help to improve such satisfaction.

An observation can be made concerning the direct effect $(\beta=0.33)$ from Empowerment of Staff to Staff Satisfaction, a continuing effect from Sustainability Visions and Vision Communication, which is larger than the direct effect $(\beta=0.16)$ from Sustainability Visions to Staff Satisfaction. This makes much sense, since Sustainability Visions alone are unlikely to make a lot of impact unless staff members are empowered to realize a vision. In such a process, they are satisfied, pending future research.

Motivation of Staff directly predicts improvements in Staff Satisfaction. It is not surprising that Motivation of Staff directly predicts improved Staff Satisfaction, since it is well recognized theoretically and empirically that motivation leads to the improvement of staff satisfaction $[75,76]$. When store managers are perceived by staff to be passionate about their vision and reward them according to the vision, their satisfaction, as measured by pay, fringe benefits, perception by others as a retail professional, and career advancement opportunities also increases.

Another observation can also be made concerning the direct effect $(\beta=0.39)$ from Motivation of Staff to Staff Satisfaction, a continuing effect from Sustainability Visions and Vision Communication, which is larger than the direct effect $(\beta=0.16)$ from Sustainability Visions to Staff Satisfaction. This is reasonable since, similar to the earlier discussion on Empowerment of Staff, Sustainability Visions alone are unlikely to make a lot of impact unless staff members are motivated to realize the visions. In such a process, they are satisfied, pending future research.

Surprisingly, Empowerment of Staff does not directly predict improvements in Motivation of Staff. Instead, it is Motivation of Staff that directly predicts improvements in Empowerment of Staff. We can draw from this surprising finding that, as part of Motivation of Staff, store managers were perceived by their staff to be passionate about their vision and reward them according to the vision. In such a context, staff might have perceived their store managers effectively delegating work to them, acting as a role model, building their self-confidence, and challenging them to do their jobs better. In addition, store manager passion and rewarding behavior may have also led to improvements in staff involvement in and commitment to the vision. These anticipated relationships are to be investigated by future research.

The present study does not take into consideration organizational alignment, given its low Cronbach's alpha value. Since organizational alignment is seen as critical in the literature, future research should continue to investigate it. Future researchers should refine the measured items before collecting their data.

Finally, although staff satisfaction can be used as a measure for corporate sustainability in the present study, as satisfied staff usually lead to improved corporate sustainability prospects, corporate sustainability can be measured in a number of other different ways. Some scholars [1] suggest that corporate sustainability can be indicated by organizational capacities to deliver strong performance, endure difficult times, and maintain market leadership, while others [77] have highlighted the triple bottom line results of economic, social and environmental performance outputs as corporate sustainability measures. In addition, sustainability outcomes of self-reliance, immunity, and resilience are found in the literature [78]. Future research may consider including them in their models.

\section{Practical Implications}

Clearly, findings from the present study offer some important managerial implications for retail store managers. First, store managers should develop a store vision statement 
that is characterized by brevity, clarity, future orientation, stability, challenges, abstractness and an ability to inspire, and which contains imageries about improving the satisfaction of a range of stakeholders, including owners, managers, employees and customers. In particular, the vision statement should contain only one overarching goal for the store, as opposed to having multiple small goals. A vision statement with these characteristics will help directly and indirectly improve staff satisfaction and very possibly that of stakeholders, which leads to long-term sustainable success. In particular, our study has revealed that simply having a vision statement, according to the Sustainability Vision theory [6], can already satisfy staff members in a retail store setting. An example of such a store vision statement is below:

"To be the best socially responsible retailer in Bangkok Metropolitan region".

Second, store managers should be trained on how to interpret their store vision statements before they start communicating and articulating their vision, to make sure that they covey the right vision message to the right functional group of people. At the same time, they should be trained on how to express their passion for their vision, reward staff according to the vision, delegate work to them, act as a role model, build their self-confidence, and challenge them to do their jobs better.

Finally, store staff should also be trained on how to use their store vision statement to guide their daily store operations. In doing so, staff will be satisfied, leading to improvements in overall store sustainability performance in the long run.

\section{Conclusions}

Among the first few reported studies on sustainability vision characteristics, the present study has answered the two research questions by constructing and testing a model using a sample of 169 retail stores in the Bangkok Metropolitan area.

Our analysis results reveal that store visions characterized by brevity, clarity, future orientation, stability, challenges, abstractness and an ability to inspire, and which contain imageries about improving sales, store leadership, and customer and staff satisfaction lead to improved sustainability prospects via increased staff satisfaction among retail stores in the Bangkok Metropolitan area. Realizing such a store vision is done through Vision Communication, Empowerment of Staff and Motivation of Staff.

The present study contributes to the theoretical literature by endorsing the Sustainability Vision theory and offering some directions for further theoretical development. These directions include the following: (a) the inclusion of other stakeholder satisfaction imageries (e.g., a surrounding community's satisfaction imagery) in vision content; (b) the inclusion of organizational alignment variables in future investigations into the relationship between sustainability vision characteristics and sustainability performance; (c) the inclusion of other sustainability performance measures, such as the Triple Bottom Line outputs and sustainability outcomes. Future research may consider testing the Sustainability Vision theory in larger organizations and different contexts.

Finally, in terms of its contribution to policy and practice, the present study offers some important managerial implications in the earlier section for retail store managers as to how they should develop and espouse a vision that leads to improved store sustainability performance.

Author Contributions: Conceptualization, S.K. and N.V.; methodology, N.V. and S.K.; software, N.V.; validation, S.K. and N.V.; formal analysis, N.V. and S.K.; investigation, N.V.; resources, N.V.; data curation, N.V.; writing—original draft preparation, N.V. and S.K.; writing-review and editing, S.K.; visualization, S.K.; supervision, S.K.; project administration, N.V. Both authors have read and agreed to the published version of the manuscript.

Funding: This research received no external funding.

Informed Consent Statement: The sample was anonymous.

Data Availability Statement: Not applicable. 
Conflicts of Interest: The authors declare no conflict of interest.

\section{References}

1. Avery, G.C. Leadership for Sustainable Futures; Edward Elgar: Northampton, MA, USA, 2005.

2. Ketprapakorn, N.; Kantabutra, S. Sustainable social enterprise model: Relationships and consequences. Sustainability 2019, 11, 3772. [CrossRef]

3. Ketprapakorn, N. Toward an Asian corporate sustainability model: An integrative review. J. Clean. Prod. 2019, $239,117995$. [CrossRef]

4. Kantabutra, S. Achieving corporate Sustainability: Toward a practical theory. Sustainability 2019, 11, 4155. [CrossRef]

5. Suriyankietkaew, S. Taking the long view on resilience and sustainability with 5Cs at B. Grimm. Glob. Bus. Organ. Excell. 2019, 38, 11-17. [CrossRef]

6. Kantabutra, S. Toward an organizational theory of sustainability vision. Sustainability 2020, 12, 1125. [CrossRef]

7. Chang, T.-W. Corporate Sustainable Development Strategy: Effect of Green Shared Vision on Organization Members' Behavior. Int. J. Environ. Res. Public Health 2020, 17, 2446. [CrossRef]

8. Nanus, B. Visionary Leadership: Creating a Compelling Sense of Direction for Your Organization; Jossey-Bass: San Francisco, CA, USA, 1992.

9. Coleman, J. Six Components of a Great Corporate Culture. Harvard Business Review Blog Network. 2013. Available online: http:/ / blogs.hbr.org/cs/2013/05/six_components_of_culture.html (accessed on 31 May 2021).

10. Collins, J.C.; Porras, J.I. Built to Last; Harper: New York, NY, USA, 2002.

11. Farinha, F.; Bienvenido-Huertas, D.; Duarte Pinheiro, M.; Silva, E.M.J.; Lança, R.; José Oliveira, M.; Batista, R. Sustainable Competitiveness of Tourism in the Algarve Region. Critical Stakeholders' Perception of the Supply Sector. Sustainability 2021, 13, 6072. [CrossRef]

12. Baumgartner, R.J. Managing corporate sustainability and CSR: A conceptual framework combining values, strategies and instruments contributing to sustainable development. Corp. Soc. Responsib. Environ. Mgmt. 2014, 21, 258-271. [CrossRef]

13. Paraschiv, D.M.; Nemoianu, E.L.; Langa, C.A.; Szabó, T. Eco-innovation, responsible leadership and organizational change for corporate sustainability. Amfiteatru Econ. 2012, 14, 404-419.

14. Kantamara, P.; Saratun, M. An analysis of CEO visions in Thailand. Int. J. Bus. Innov. Res. 2017, 12, 23-40. [CrossRef]

15. Senge, P.M. The Fifth Discipline: The Art E Practice of the Learning Organization; Currency Doubleday: New York, NY, USA, 1990.

16. O'Connell, D.; Hickerson, K.; Pillutla, A. Organizational visioning: An integrative review. Group Organ. Manag. 2011, 36, 103-125. [CrossRef]

17. Mumford, M.D.; Strange, J.M. The origins of vision: Effects of reflection, models, and analysis. Leadersh. Q. 2005, 16, 121-148.

18. Chang, T.-W.; Chen, F.-F.; Luan, H.-D.; Chen, Y.-S. Effect of Green Organizational Identity, Green Shared Vision, and Organizational Citizenship Behavior for the Environment on Green Product Development Performance. Sustainability 2019, 11, 617. [CrossRef]

19. Rampersad, H.K. Total Quality Management: An Executive Guide to Continuous Improvement; Springer: Heidelberg, Germany, 2001.

20. Ford, J.D.; Pasmore, W.A. Vision: Friend or foe during change? J. Appl. Behav. Sci. 2006, 42, 172-176. [CrossRef]

21. Stam, D.; Lord, R.G.; van Knippenberg, D.; Wisse, B. An image of who we might become: Vision communication, possible selves, and vision pursuit. Organ. Sci. 2014, 25, 1172-1194. [CrossRef]

22. Baum, I.R.; Locke, E.A.; Kirkpatrick, S.A. A longitudinal study of the relation of vision and vision communication to venture growth in entrepreneurial firms. J. Appl. Psychol. 1998, 83, 43-54. [CrossRef]

23. Kantabutra, S.; Vimolratana, P. Vision-based leadership: Relationships and consequences in Thai and Australian retail stores. Asia-Pac. J. Bus. Adm. 2009, 1, 165-188. [CrossRef]

24. Jick, T. Vision is $10 \%$, implementation is the rest. Bus. Strategy Rev. 2001, 12, 36-38. [CrossRef]

25. Carton, A.M.; Lucas, B.J. How can leaders overcome the blurry vision bias? Identifying an antidote to the paradox of vision communication. AMJ 2018, 61, 2106-2129. [CrossRef]

26. Avery, G.C.; Bergsteiner, H. Sustainable Leadership: Honeybee and Locust Approaches; Routledge: New York, NY, USA, 2011.

27. Venus, M.; Johnson, R.E.; Zhang, S.; Wang, X.-H.; Lanaj, K. Seeing the big picture: A within-person examination of leader construal level and vision communication. J. Manag. 2019, 45, 2666-2684. [CrossRef]

28. Daft, R.L. The Leadership Experience; Thomson South-Western: Mason, OH, USA, 2005.

29. Priem, R.L.; Rosenstein, J. Is organization theory obvious to practitioners? A test of one established theory. Organ. Sci. 2000, 11, 509-524. [CrossRef]

30. Kantabutra, S. Negative vision effect in Thai retail stores. Singap. Manag. Rev. 2010, 32, 1-28.

31. Parikh, J.; Neubauer, F. Corporate visioning. In International Review of Strategic Management; Hussey, D.E., Ed.; Wiley: Chichester, UK, 1993; Volume 4, pp. 105-116.

32. Kotter, J.P. What leaders really do. Harv. Bus. Rev. 2001, 79, 85-98.

33. Carson, C.M.; King, J.E. Leaving leadership: Solving leadership problems through empowerment. Manag. Decis. 2005, 43, 1049-1053. [CrossRef]

34. Forrester, R. Empowerment: Rejuvenating a potent idea. Acad. Manag. Exec. 2000, 14, 67-80. [CrossRef]

35. Tarnow, E. A recipe for mission and vision statements. J. Mark. Pract. Appl. Mark. Sci. 1997, 3, 184-189. [CrossRef]

36. Čuić Tanković, A. Defining Strategy using Vision and Mission Statements of Croatian Organizations in Times of Crisis. Econ. Res. Ekon. Istraživanja 2013, 26, 331-342. [CrossRef] 
37. Katz, J. How Emotions Work; University of Chicago Press: Chicago, IL, USA, 1999.

38. Bandura, A. Fearful expectations and avoidant actions as coeffects of perceived self-inefficacy. Am. Psychol. 1986, 41, 1389-1391. [CrossRef]

39. Ukko, J.; Karhu, J.; Pekkola, S. Employees satisfied with performance measurement and rewards: Is it even possible? Int. J. Bus. Excell. 2009, 2, 1-15. [CrossRef]

40. Maciariello, J.A.; Peter, F. Drucker on executive leadership and effectiveness. In The Leader of the Future; Hesselbein, F., Goldsmith, M., Eds.; Jossey-Bass: San Francisco, CA, USA, 2006; pp. 3-27.

41. Gecas, V.; Self, M.A. Social class and self-esteem: Psychological centrality, compensation, and the relative effects of work and home. Soc. Psychol. Q. 1990, 53, 165-173. [CrossRef]

42. Karnama, A.; Vinuesa, R. Organic Growth Theory for Corporate Sustainability. Sustainability 2020, 12, 8523. [CrossRef]

43. Wayne, F.C. Managing Human Resource: Productivity, Quality of Work Life Profits; McGraw-Hill: New York, NY, USA, 2006.

44. Buitendach, J.H.; Witte, H.D. Job insecurity, extrinsic and intrinsic job satisfaction and affective organisational commitment of maintenance workers in a parastatal. S. Afr. J. Bus. Manag. 2005, 36, 27-37. [CrossRef]

45. Newman, B.M.; Newman, P.R. Theories of Adolescent Development; Academic Press: London, UK, 2020.

46. Bektaş, Ç. Explanation of intrinsic and extrinsic job satisfaction via mirror model. BMIJ 2017, 5, 627-639. [CrossRef]

47. Gagné, M.; Deci, E.L. Self-determination theory and work motivation. J. Organ. Behav. 2005, 26, 331-362. [CrossRef]

48. Bontis, N.; Richards, D.; Serenko, A. Improving service delivery: Investigating the role of information sharing, job characteristics, and employee satisfaction. Learn. Organ. 2011, 18, 239-250. [CrossRef]

49. Slavitt, D.; Stamps, P.; Piedmont, E.; Hasse, A. Index of Work Satisfaction; University of Michigan Press: Ann Arbor, MI, USA, 1986.

50. Collis, J.; Hussey, R. Business Research: A Practical Guide for Students; Red Globe Press: London, UK, 2021.

51. Park, Y.S.; Konge, L.; Artino, A.R., Jr. The positivism paradigm of research. Acad. Med. 2020, 95, 690-694. [CrossRef] [PubMed]

52. Buelens, B.; Burger, J.; van den Brakel, J.A. Comparing inference methods for non-probability samples. Int. Stat. Rev. 2018, 86, 322-343. [CrossRef]

53. Kantabutra, S. Examining store manager effects in consumer and staff satisfaction: Evidence from Thailand. J. Retail. Consum. Serv. 2011, 18, 46-57. [CrossRef]

54. Kantabutra, S.; Avery, G.C. Vision effects in customer and staff satisfaction: An empirical investigation. Leadersh. Organ. Dev. J. 2007, 28, 209-229. [CrossRef]

55. Cohen, R.J.; Swerdik, M.E.; Phillips, S.M. Psychological Testing and Assessment: An Introduction to Tests and Measurement; Mayfield: Mountain View, CA, USA, 1996; p. 685.

56. Lavrakas, P.J. Encyclopedia of Survey Research Methods; Sage Publications: Thousand Oaks, CA, USA, 2008.

57. Krumpal, I. Determinants of social desirability bias in sensitive surveys: A literature review. Qual. Quant. 2013, 47, 2025-2047. [CrossRef]

58. Podsakoff, P.M.; MacKenzie, S.B.; Lee, J.; Podsakoff, N.P. Common methods biases in behavioral research: A critical review of the literature and recommended remedies. J. Appl. Psychol. 2003, 88, 879-903. [CrossRef] [PubMed]

59. Jakobsen, M.; Jensen, R. Common method bias in public management studies. Int. Public Manag. J. 2015, 18, 3-30. [CrossRef]

60. Richardson, H.A.; Simmering, M.J.; Sturman, M.C. A tale of three perspectives: Examining post hoc statistical techniques for detection and correction of common method variance. Organ. Res. Methods 2009, 12, 762-800. [CrossRef]

61. Landis, J.R.; Koch, G.G. The measurement of observer agreement for categorical data. Biometrics 1977, 33, 159-174. [CrossRef]

62. Hair, J.F.; Black, W.C.; Babin, B.J.; Anderson, R.E. Multivariate Data Analysis; Pearson: London, UK, 2014.

63. Pathak, P.; Singh, M.P.; Badhotiya, G.K. Performance obstacles in sustainable manufacturing—model building and validation. J. Adv. Manag. Res. 2020, 17, 549-566. [CrossRef]

64. Anderson, J.C.; Gerbing, D.W. Structural equation modeling in practice: A review and recommended two-step approach. Psychol. Bull. 1988, 103, 411-423. [CrossRef]

65. Santisteban, C. Psicometría: Teoría y Practica en la Construcción de Test; Ediciones Norma: Madrid, Spain, 1990.

66. Hair, J.F.; Ringle, C.M.; Sarstedt, M. PLS-SEM: Indeed a silver bullet. J. Mark. Theory Pract. 2011, 19, 139-152. [CrossRef]

67. Hair, J.F.; Black, W.C.; Babin, B.J.; Anderson, R.E. Multivariate Data Analysis; Prentice Hall: Hoboken, NJ, USA, 2010.

68. Kline, R.B. Methodology in the Social Sciences. In Principles and Practice of Structural Equation Modeling; Guilford Press: New York, NY, USA, 2016.

69. Wang, J.; Wang, X. Structural Equation Modeling Applications Using Mplus; John Wiley \& Sons: Chichester, UK, 2012.

70. Pallant, J. SPSS Survival Manual: A Step by Step Guide to Data Analysis Using SPSS for Windows; Open University Press: Buckingham, $\mathrm{UK}, 2005$.

71. Marsh, H.W.; Hocevar, D. Application of confirmatory factor analysis to the study of self-concept: First-and higher order factor models and their invariance across groups. Psychol. Bull. 1985, 97, 562-582. [CrossRef]

72. Down, C.W.; Conrad, C. A Critical Incident Study of Superior-Subordinate Communication. In Proceedings of the Academy of Management Convention, San Francisco, CA, USA, 8-11 August 1978.

73. Chhotray, S.; Sivertsson, O.; Tell, J. The roles of leadership, vision, and empowerment in born global companies. J. Int. Entrep. 2018, 16, 38-57. [CrossRef]

74. Mohd Adnan, S.N.S.; Valliappan, R. Communicating shared vision and leadership styles towards enhancing performance. Int. J. Product. Perform. Manag. 2019, 68, 1042-1056. [CrossRef] 
75. Pang, K.; Lu, C.-S. Organizational motivation, employee job satisfaction and organizational performance. Marit. Bus. Rev. 2018, 3, 36-52. [CrossRef]

76. Igalens, J.; Roussel, P. A study of the relationships between compensation package, work motivation and job satisfaction. J. Organ. Behav. 1999, 20, 1003-1025. [CrossRef]

77. Elkington, J. Accounting for the triple bottom line. Meas. Bus. Excell. 1998, 2, 18-22. [CrossRef]

78. Avery, G.C.; Bergsteiner, H. Sufficiency Thinking; Routledge: New York, NY, USA, 2020. 